\title{
Influence of ground surface characteristics on the mean radiant temperature in urban areas
}

Article

Accepted Version

Lindberg, F., Onomura, S. and Grimmond, C. S. B. (2016) Influence of ground surface characteristics on the mean radiant temperature in urban areas. International Journal of Biometeorology, 60 (9). pp. 1439-1452. ISSN 1432-1254 doi: https://doi.org/10.1007/s00484-016-1135-x Available at https://centaur.reading.ac.uk/58036/

It is advisable to refer to the publisher's version if you intend to cite from the work. See Guidance on citing.

To link to this article DOI: http://dx.doi.org/10.1007/s00484-016-1135-x

Publisher: Springer

All outputs in CentAUR are protected by Intellectual Property Rights law, including copyright law. Copyright and IPR is retained by the creators or other copyright holders. Terms and conditions for use of this material are defined in the End User Agreement.

www.reading.ac.uk/centaur 
Central Archive at the University of Reading

Reading's research outputs online 


\title{
Influence of ground surface characteristics on the mean radiant temperature in urban areas
} Fredrik Lindberg ${ }^{1}$, Shiho Onomura ${ }^{1}$, C.S.B. Grimmond ${ }^{2}$

University of Gothenburg, Göteborg Urban Climate Group, Earth Science Centre, Box 460, SE-405 30 Gothenburg, Sweden University of Reading, Meteorology, UK

\begin{abstract}
The effect of variations in land cover on mean radiant surface temperature $\left(T_{m r t}\right)$ is explored through a simple scheme developed within the radiation model SOLWEIG. Outgoing longwave radiation is parameterised using surface temperature observations on a grass and an asphalt surface, whereas outgoing shortwave radiation is modelled through variations in albedo for the different surfaces. The influence of surface materials on $T_{m r t}$ is small compared to the effects of shadowing. Nevertheless, altering ground surface materials could contribute to a reduction on $T_{m r t}$ to reduce the radiant load during heat-wave episodes in locations where shadowing is not an option. Evaluation of the new scheme suggests that despite its simplicity it can simulate the outgoing fluxes well, especially during sunny conditions. However, it underestimates at night and in shadowed locations. One grass surface used to develop the parameterisation, with very different characteristics compared to an evaluation grass site, caused $T_{m r t}$ to be underestimated. The implications of using high resolution (e.g. 15 minutes) temporal forcing data under partly cloudy conditions are demonstrated even for fairly proximal sites.
\end{abstract}

Keywords: SOLWEIG; surface temperature; Gothenburg; London

\section{$1 \quad$ Introduction}

Increasing attention is being directed to how urban planners can design, build and retrofit cities to improve outdoor thermal comfort conditions to enhance the health and well-being of urban citizens, i.e. to reduce heat and cold stress as well as prolong periods of comfortable conditions (see, for example, Müller et al. 2014 and Erell et al. 2014).

Mean radiant temperature $\left(T_{m r t}\right)$ is one of the most important meteorological parameters governing the human energy balance and thermal comfort outdoors, especially during clear and calm summer days (Mayer and Höppe 1987). $T_{m r t}$ is the net result of all short- and longwave radiation fluxes from the surroundings to which a human body is exposed. When compared to other variables influencing thermal comfort, such as air temperature $\left(T_{a}\right)$ and humidity, $T_{m r t}$ shows larger spatial variation over short distances (Ali Toudert and Mayer 2007; Lindberg et al. 2013). Comparison of $T_{a}$ and $T_{m r t}$ in adjacent sunlit and shaded locations during warm and clear summer weather by Mayer et al. (2008) documenteed that differences in $T_{m r t}$ could be as much as $37^{\circ} \mathrm{C}$, whereas differences in $T_{a}$ were only $1-2^{\circ} \mathrm{C}$.

$T_{m r t}$ has been proposed as a better metric to analyze the impact of weather and climate on people's health than air temperature or apparent temperature (Thorsson et al. 2014). Thus improving knowledge of how $T_{m r t}$ varies within the urban environment is important. In this study, variations related to different weather conditions urban morphology and vegetation on radiative properties, and thus $T_{m r t}$, are explored. Insights into these variation and their controls are needed to more accurately identify thermal comfort risk areas and to inform appropriate measures to reduce heat stress.

The relative importance of shortwave and longwave radiation fluxes on a human vary spatially and temporally in cities with season and urban density and morphology. For a standing man during clear, calm and warm weather situations, in Freiburg, Germany the short and longwave fluxes are of equal importance (Ali-Toudert and Mayer 2007). However, longwave fluxes become increasingly important in denser environments, with increased radiant fluxes from walls (Lindberg et al. 2013). The relation between shortwave and longwave radiant load changes through time as the incidence angle of shortwave radiation varies depending on day of year and latitude. The spatial variations of daytime $T_{m r t}$ are chiefly influenced by shadow patterns, i.e. variations in direct shortwave radiation, affected by obstructing objects such as trees, buildings and general topography (Lindberg and Grimmond 2011b). Shadowing, primarily from trees and bushes, as a potential method to reduce daytime heat stress, is a relatively easy mitigation measure in urban development (Andersson-Sköld et al. 2015).

Although thermal and radiative properties of surrounding surface materials (albedo, emissivity, thermal admittance etc.) could be an option to regulate the outdoor thermal environment, they usually have a minor effect. Local scale simulations (Erell et al. 2014) showed that although high-albedo surfaces (both canyon floor and walls) may reduce the air temperature to which pedestrians are exposed, the change in temperature has only a small effect on their thermal balance with the environment. Reduction in surface temperatures by increasing the albedo of urban surfaces, leading to a reduction in longwave radiation fluxes, is counterbalanced by increased reflection of shortwave radiation. Thus, the net effect is minor in terms of the thermal environment in outdoor urban settings. However, changes in materials will affect heat storage and indoor building temperatures and these effects may be significant (Erell et al. 2014).

$T_{m r t}$ can be accurately measured using pyranometers (shortwave) and pyrgeometers (longwave). This approach commonly uses six sensors (aligned for the four horizontally and vertically, from the four cardinal points (see Thorsson 
et al. 2007, their Figure 2), along with information on body posture (sitting, standing etc.) and absorption coefficients of shortwave and longwave) radiation of the human body (Höppe 1992). However, the need for measurements in six directions makes it costly, spatially limited and difficult to implement in extensive measurement campaigns (Thorsson et al. 2007a). Simpler methods use a globe thermometer along with air temperature and wind speed observations (Nikolopoulou et al. 1999) but are also spatially constrained.

Several models have been developed to derive $T_{m r t}$. One popular option is the 1D model, RayMan (Matzarakis et al. 2007; Matzarakis et al. 2009). The model offers several estimation and input possibilities. An alternative is the SOlar and LongWave Environmental Irradiance Geometry (SOLWEIG) model (Lindberg et al. 2008, Lindberg and Grimmond $2011 b$ ), a 2D radiation model for estimating radiation fluxes and thus $T_{m r t}$ in urban environments. Another model, extensively used in urban climate and thermal comfort studies, is ENVI-met (Bruse and Fleer 1998). ENVI-met is a userfriendly, three-dimensional micro climate computer model able to simulate the interactions between different urban surfaces, vegetation and the atmosphere at typical scales of 0.5 to 10 meters and at maximum time step of 10 seconds. A model inter-comparison between the three models mentioned can be found in Chen et al. (2014).

In this paper, the influence of micro scale ground surface types on radiation fluxes and $T_{m r t}$ is explored. Observations on surface temperatures for different surfaces are considered and a simple land cover scheme is developed and evaluated using the SOLWEIG model (further developed here). Diurnal patterns of radiation fluxes and related $T_{m r t}$ are also investigated. This study is part of a more extensive work where SOLWEIG will be incorporated into The Urban Multiscale Environmental Predictor (UMEP) a climate sensitive planning tool for architects, planners and researchers (Lindberg et al. 2015b).

\section{METHODS}

\subsection{SOLWEIG}

The SOLWEIG model follows the same approach commonly adopted to observe $T_{m r t}$ (as used, for example, by Höppe, 1992), with shortwave and longwave radiation fluxes from six directions being individually calculated to derive $T_{m r t}$. The SOLWEIG-model is available as 2D and 1D versions. Evaluations of SOLWEIG (Lindberg and Grimmond 2011b, Lindberg et al. 2008, Chen et al. 2014, Lau et al. 2015) have been undertaken for a number of locations in e.g. Gothenburg, Freiburg, Kassel and Hong Kong. The model requires weather time-series at any time resolution (> 1 minute) for ambient air temperature $\left(T_{a}\right)$, relative air humidity $(R H)$, global $(G)$ and diffuse $(D)$ solar radiation, together with a digital surface model (DSM) and site geographical location (i.e. latitude, longitude, and altitude). As diffuse and/or direct $(I)$ solar radiation are not commonly available, the model also allows calculation of $D$ from $G$ in conjunction with $T_{a}$ and $R H$, using the Reindl et al. (1990) approach. Direct shortwave radiation on a surface perpendicular to the Sun is then estimated:

$$
I=(G-D) / \sin \eta
$$

where $\eta$ is the Sun's altitude angle above the horizon. Additional DSMs can be added to account for vegetation in the form of trees and bushes. $T_{m r t}$ is usually calculated for a standing person, with the angular factors $(F)$ specifying the proportion of radiation received from each direction set to 0.22 for east, west, north and south, and 0.06 for radiation fluxes from above and below (Fanger 1970). Absorption coefficients of shortwave ( $\xi \mathrm{k})$ and longwave ( $\varepsilon \mathrm{p})$ radiation for a human body are 0.7 and 0.97, respectively (Höppe 1992; VDI 1998). Albedo $(\alpha)$ and emissivity $(\varepsilon)$ for buildings and vegetation are assumed to be the same and are set to 0.20 and 0.95 , respectively. The transmissivity of shortwave and longwave radiation through foliated vegetation $(\tau)$ are $2 \%$ and $0 \%$, respectively (Lindberg and Grimmond 2011b; Konarska et al. 2014). Neither wind fields nor variations in building wall materials are considered in the current version of the model.

In order to determine $T_{m r t}$, (units: $\mathrm{K}$ ) the mean radiant flux density $(R)$ is calculated, which is defined as the sum of all fields of long $\left(L_{i}\right)$ and shortwave $\left(K_{i}\right)$ radiation in three dimensions $(i=1-6)$, together with the angular $(F)$ and absorption factors of an individual (VDI 1994):

$$
R=\xi_{k} \sum_{i=1}^{6} K_{i} F_{i}+\varepsilon_{p} \sum_{i=1}^{6} L_{i} F_{i}
$$

From $R$ the $T_{m r t}$ is calculated from Stefan Boltzmann's law, (see eq. 2 in Lindberg et al. 2008). The incoming shortwave radiation $\left(\mathrm{K}_{\downarrow}\right)$ for a grid cell $(\mathrm{x}, \mathrm{y})$ is a function of $D, I$ and $G$, as well as view factors $(\Psi)$. For clarity, the equations are written without the spatial subscript:

$$
\begin{aligned}
K_{\downarrow}=I\left[S_{b}-\left(1-S_{v}\right)(1-\tau)\right] \sin \eta+D\left[\Psi_{s k y b}-\left(1-\Psi_{s k y v}\right)(1-\tau)\right]+ \\
\quad \alpha_{w}\left[1-\left(\Psi_{s k y b}-\left(1-\Psi_{s k y v}\right)(1-\tau)\right)\right]\left(G\left(1-f_{s}\right)+D f_{s}\right)
\end{aligned}
$$

where $S$ accounts for shadow as a Boolean value (presence $=0$ or absence $=1$ ), for buildings (subscript $b$ ) and vegetation $(v)$; the subscripts associated with $\Psi$ indicate what aspects are being accounted for (e.g. sky seen by building); and $\alpha_{w}$ is the bulk albedo of walls. For a detailed description of how shadows and sky view factors are generated using raster DSMs, see Lindberg and Grimmond (2010) and Lindberg and Grimmond (2011b). $f_{s}$ is the fraction of wall that is 
shadowed (Lindberg et al. 2008). The first and second terms on the right-hand side of (3) represent direct and diffuse radiation fluxes, respectively. The third term in (3) is a simplified representation of reflected radiation. Incoming longwave radiation $\left(L_{\downarrow}\right)$ is estimated using an equation modified from Jonsson et al. (2006): $L_{\downarrow}=\left(\Psi_{s k y b}+\Psi_{\text {sky } v}-1\right) \varepsilon_{s k y} \sigma T_{a}^{4}+\left(2-\Psi_{\text {sky } v}-\Psi_{\text {sky } v b}\right) \varepsilon_{\text {wall }} \sigma T_{a}^{4}+$

$$
\left(\Psi_{\text {sky } v b}-\Psi_{\text {sky } b}\right) \varepsilon_{\text {wall }} \sigma T_{s}^{4}+\left(2-\Psi_{\text {sky } b}-\Psi_{\text {sky } v}\right)\left(1-\varepsilon_{\text {wall }}\right) \varepsilon_{\text {sky }} \sigma T_{a}^{4}
$$

where $\varepsilon_{s k y}$ and $\varepsilon_{\text {wall }}$ are the sky and wall emissivities and $T_{s}$ is the average surface temperature of building walls and the ground. $T_{a}$ is ambient air temperature and $\sigma$ is the Stefan Boltzmann constant. All temperatures are in Kelvin. Estimation of $T_{s}$ is described in Section 2.2. The first term on the right-hand side is the direct sky longwave radiation, the second is the radiation originating from vegetation, the third is the wall radiation and the fourth is the reflected sky radiation. For a detailed description of the estimation of $\varepsilon_{s k y}$, as well as how $L_{\downarrow}$ is modified based on cloud cover, see Lindberg et al. (2008).

The shortwave radiation from the four cardinal points $\left(\mathrm{K}_{\rightarrow}\right)$ is estimated as follows (exemplified by the easterly component, subscript $E$ ):

If the sun azimuth angle $(\theta)$ is $\theta>0^{\circ}$ and $\theta \leq 180^{\circ}$ :

otherwise:

$$
K_{\rightarrow E}=I\left[S_{b}-\left(1-S_{v}\right)(1-\tau)\right] \cos \eta \sin \vartheta+\left(\begin{array}{c}
D[1-w]+ \\
\alpha_{w a l l}\left[G w\left(1-f_{s}\right)+D w f_{s}\right]+K_{\uparrow E}
\end{array}\right) \times 0.5
$$

$$
K_{\rightarrow E}=\left(\begin{array}{c}
D[1-w]+ \\
\alpha_{\text {wall }}\left[w\left(G\left(1-f_{s}\right)+D f_{s}\right)\right]+K_{\uparrow E}
\end{array}\right) \times 0.5
$$

The integrative angular weighting factors (w), explained in detail in Lindberg et al. (2008) and Lindberg and Grimmond (2011b), represents the amount of radiation originating from either building walls, vegetation or sky, as well as all reflecting surfaces seen by a sensor perpendicular to the wall thus $w$, as used in eq. 5 and 6 requires the angular factor for buildings $\left(w_{\text {Ewall }}\right)$ and vegetation $\left(w_{\text {Eveg }},\right)$ :

$$
w=w_{\text {Ewall }}+w_{\text {Eveg }}(1-\tau)
$$

$K_{\uparrow E}$ represents outgoing shortwave radiation (see Section 2.2). For all radiation components except for the direct radiation from the Sun, only half of the hemisphere is taken into account hence, all are multiplied by 0.5 .

The longwave radiation from each of the cardinal points are estimated using the following (exemplified again for the easterly component):

$$
\begin{aligned}
& L_{\rightarrow E_{-} \text {sky }}=\left(\Psi_{\text {sky Eb }}+\Psi_{\text {sky Ev }}-1\right) \varepsilon_{\text {sky }} \sigma T_{a}^{4} w_{E s k y} \times 0.5 \\
& L_{\rightarrow E_{-} \text {veg }}=\varepsilon_{\text {wall }} \sigma T_{\text {veg }}^{4} w_{E v e g} \times 0.5 \\
& L_{\rightarrow E_{-} \text {ground }}=L_{\uparrow E} \times 0.5 \\
& L_{\rightarrow E_{-} \text {reflected }}=\left(L_{\downarrow}+L_{\uparrow}\right) w_{\text {Erefl }}\left(1-\varepsilon_{\text {wall }}\right) \times 0.5 \\
& \text { if } \theta>0^{\circ} \text { and } \theta \leq 180^{\circ}: \\
& L_{\rightarrow E_{-} \text {sunlit }}=\varepsilon_{\text {wall }} \sigma\left(T_{a}^{4}+T_{\text {wall }}^{4} \sin \vartheta\right) w_{\text {Ewall }}\left(1-f_{s w}\right) \cos \eta \times 0.5 \\
& L_{\rightarrow E_{-} \text {shadow }}=\varepsilon_{\text {wall }} \sigma T_{a}^{4} w_{E \text { wall }} f_{s} \times 0.5
\end{aligned}
$$

otherwise:

$$
\begin{aligned}
& L_{\rightarrow E_{-} S U N}=0 \\
& L_{\rightarrow E_{-} S H A D O W}=\varepsilon_{\text {wall }} \sigma T_{a}^{4} w_{\text {Ewall }} \times 0.5
\end{aligned}
$$

$\mathrm{L} \uparrow \mathrm{E}$ represents outgoing shortwave radiation (see Section 2.2)

\subsection{Ground cover scheme}

The new ground cover scheme modifies the outgoing shortwave and longwave fluxes. The outgoing shortwave radiation for each pixel within a model domain is estimated as:

$K_{\uparrow}=\Psi_{\text {gsunlit }(\alpha)} I \sin \eta+\Psi_{g A l l(\alpha)}\left(\begin{array}{c}D\left[\Psi_{\text {sky } b}-\left(1-\Psi_{\text {sky } v}\right)(1-\tau)\right]+ \\ \alpha_{w}\left[1-\left(\Psi_{\text {sky } b}-\left(1-\Psi_{\text {sky } v}\right)(1-\tau)\right)\right]\left(G\left(1-f_{s}\right)+D f_{s}\right)\end{array}\right)$

where $\Psi_{g S \text { Sunlit }(\alpha)}$ is the albedo dependent ground view factor for sunlit surfaces influencing a single reflection of direct radiation from the ground. $\Psi_{g A l l}(\alpha)$ is the albedo dependent ground view factor including both sunlit and shadowed areas. Previously, $\Psi_{g}$ was dependent only on the horizontal shadow patterns and was a measure with respect to the amount of sunlit area on the ground seen at a point above the ground. This height $(\mathrm{z}=1.1 \mathrm{~m})$ represents the centre of mass of a standing human but can be altered accordingly. When $\Psi_{g}=1$, only sunlit surfaces are seen from that specific pixel. $\Psi_{g}$ use the simple relation that half the radiative surface influence originates from an area with a radius equal to the 'sensor' height (Schmid et al. 1991). For each pixel a search is conducted at $20^{\circ}$ intervals between $0^{\circ}$ and $359^{\circ}$. In order not to increase the computational time too much, the maximum search distance is set to 20 times the height of interest (e.g. 22 $\mathrm{m}$ when $\mathrm{z}=1.1 \mathrm{~m}$ ). The major difference from previous versions of SOLWEIG (from v2.0), is that the ground view factor 
$\left(\Psi_{g(\alpha)}\right)$ is now affected by pixel-wise albedo variations. Albedo values for each pixel are based on the ground cover type specified. This information is included in the new grid with the same pixel resolution and extent as the ground and building DSM. The shadow casting algorithm (Ratti and Richens 1999; Ratti and Richens 2004) now includes detailed information about the sunlit fractions on building walls (Lindberg et al. 2015a). This impacts the estimation of $\Psi_{g S u n l i t}(\alpha)$ when ground pixels located closer than the maximum search distance to a wall in any direction are taken into account. The land cover can have different material types (e.g. Figure 1c has four) each with its own albedo (Table 1). The shadow patterns on the ground (Figure 1b) originate from buildings, topography, trees and bushes within the model domain (see Lindberg and Grimmond 2011 for details). Figure 1d shows $\Psi_{g S u n l i t(\alpha)}$ for the same time. The strong influence of shadow patterns on $\Psi_{g S u n l i t(\alpha)}$ is evident. The impact of the various land cover types is relatively small except for the water surface, with the lowest albedo $(\alpha=0.05)$. Also of note is the strong contrast in between nearby pixels, as expected from the Schmid et al. (1991). The $\Psi_{g A l l(\alpha)}$, (Figure 1e) resembles strongly the original land cover image in Figure 1c. What is particularly evident is the influence of the water body to adjacent areas (lower part of the image). The resulting spatial variations of $K_{\uparrow}$ (Figure 1f) are mainly caused by the shadow patterns, whereas the variations in surface cover have a minor effect. As SOLWEIG is developed to estimate $T_{m r t}$ at ground level, where people are, building roof pixels are not included in the ground view factors calculated. Instead one single albedo value is used at roof level. Nevertheless, $T_{m r t}$ are roof level is still calculated.

The longwave radiation fluxes throughout the model domain are estimated according to:

$$
L_{\uparrow}=\Psi_{g}\left[\varepsilon_{\text {ground }(i)} \sigma\left(T_{a}+\left(S_{b}-\left(1-S_{v}\right)(1-\tau)\right)\left(T_{s}-T_{a}\right)\right)^{4}\right]
$$

where $\varepsilon_{\text {ground }(i)}$ is the emissivity of the specific land cover (Figure $1 \mathrm{c}$ and Table 1) and $T_{s}$ is the surface temperature for each land cover type following Bogren et al. (2000). They related surface temperature on sun-exposed surfaces based on simple linear relations between maximum solar elevation and maximum difference between $T_{a}$ and $T_{s}$ assessed under clear day conditions (Lindberg et al. 2008). Based on ground cover type, the maximum difference between surface and air temperature $\left(T_{\text {diffmax }}\right)$ is considered to occur sometime after the maximum solar elevation is reached (see Section 2.3, Table 1). $T_{s}$ for a clear day is assumed to be sinusoidal, where the amplitude and initial morning values of $T_{s}$ are derived from the linear relation presented in Section 2.3 (see $\mathrm{T}_{\mathrm{s}} / \eta_{\max }$; Table 1). The period of the sinusoidal equation for a particular day of the year is determined based on the time between sunrise of the day of interest and time of $T_{\text {diffmax }}$. For non-clear model runs, $T_{\text {diffmax }}$ is reduced by the Clearness Index (Crawford and Duchon 1999) at the ground surface as explained in Lindberg et al. (2008). When ground surface pixels change from sun exposed to shadowed, the new surface temperature value would not instantly be equal to $T_{a}$ but instead, a linear decrease where surface temperature is assumed to be $75 \%$ of the calculated sun-exposed surface temperature after 60 minutes. If a pixel is shadowed for two sequential hours (120 $\mathrm{min}), T_{s}$ is set to $T_{a}$. This approach is adopted based on the thermal properties of ground surfaces and the gradual temperature drop evident when a surface location becomes shadowed. Similarly, a gradual temperature rise is evident when a given pixel change from shadowed into a sun-exposed area. The surface temperature of water surfaces is derived from a diurnal average air temperature for the specific day of interest. The outgoing longwave radiation for the same model domain, time and location (Gothenburg, Sweden, at $2 \mathrm{pm}$ on the $26^{\text {th }}$ of July, 2006) is shown in Figure 2 a. The shadow patterns (Figure 1b) have the main influence on the outgoing longwave fluxes, but compared to $K_{\uparrow}$, the surface materials have a large impact on the spatial variations of $L_{\uparrow}$ (compare Figure 1c and 1f). Notable is that the highest values of $L_{\uparrow}$ are found near sunlit south-facing walls.

The outgoing radiation included in the derivation of radiation fluxes from the cardinal points (e.g. $K_{\uparrow E}$ and $L_{\uparrow E}$ ) uses the same concepts as described above. The difference is that radiation flux from a cardinal point (e.g. East) should only include ground pixels located east of a certain point of interest. For example, the easterly component only incorporates pixels that fall within $180^{\circ}$ and $360^{\circ}$ from a pixel where $K_{\uparrow E}$ and $L_{\uparrow E}$ are calculated. Although the shortwave radiation for the southerly (Figure 2b) and the northerly (Figure 2c) components are similar, clear differences are evident, such as near the water body in the lower part of the images.

By inserting the 12 components of radiative fluxes into Eq. 2, $T_{m r t}$ is derived (Figure 2d). The shadow patterns are the dominant feature affecting the spatial variations of $T_{m r t}$; the ground cover contributes to a much lesser extent (see Section 4). Even though the direct solar radiation is high $\left(I=728.3 \mathrm{~W} \mathrm{~m}^{-2}\right)$, for the hour considered (Figures 1 and 2) the sky is not totally clear $\left(G=766.1 \mathrm{~W} \mathrm{~m}^{-2}\right.$ and $D=194.8 \mathrm{~W} \mathrm{~m}^{-2}$ ). Therefore the warmest areas close to sunlit walls found during clear sky conditions cannot be identified in Figure 2d. Similar results were documented in (Lindberg et al. 2013).

\subsection{Surface temperature parameterisation}

Measurements of surface temperatures for two different types of surfaces (short grass and dark-coloured asphalt) were conducted to obtain relations between solar elevation and $T_{\text {diffmax }}$ for the $T_{s}$ estimation of the surfaces (see section 2.2). The measurement site $\left(57^{\circ} 46^{\prime} \mathrm{N} 11^{\circ} 51^{\prime} \mathrm{E}\right)$ in an open field adjacent to Gothenburg City Airport were conducted from $1 \mathrm{st}$ July 2011 - 31st December 2012. Infrared radiometers (Apogee, SI-111), with an accuracy of $0.2^{\circ} \mathrm{C}$ between -20 and 
$65^{\circ} \mathrm{C}$ were located $0.5 \mathrm{~m}$ above the ground surfaces, looking vertically downward. The grass was cut about every three weeks from April to October. The soil is clay-rich with very high water retention. Air temperature and relative humidity were obtained from the meteorological station at the airport. Global radiation and air pressure were observed at the Department of Earth Sciences, the University of Gothenburg roof-top meteorological station $12 \mathrm{~km}$ south-east of the airport. To select clear and sunny days, the clearness index of the sky was calculated as the ratio of the measured solar irradiance to the clear-sky irradiance based on the Crawford and Duchon (1999) method using air temperature and relative humidity. The method was modified by Lindberg et al. (2008) to correct for the underestimation of the clearness index when the altitude of the sun is low. Clear-sky conditions were defined as clearness index $\geq 0.9$. $T_{\text {diffmax }}$ was calculated as the maximum difference between surface and air temperature $(\mathrm{N}=71)$.

Analysis of the timing of $T_{\text {diffmax }}$ for the different surfaces (not shown) revealed the most frequent occurrence of $T_{\text {diffmax }}$ for asphalt and grass occurred at $3 \mathrm{pm}$ and $2 \mathrm{pm}$ (local time), respectively. These occurrences were also incorporated as a parameterisation variable in the new land cover scheme i.e. when the sinusoidal temperature wave has its maximum. $T_{\text {diffmax }}$ increases with higher $\eta_{\max }$ at different rates for asphalt and grass (Figure 3 ). The high coefficient of determination for the asphalt surface $\left(\mathrm{R}^{2}=0.93\right)$, compared to the grass surface $\left(\mathrm{R}^{2}=0.67\right)$, can be explained by the more dynamic biophysical properties of the grass surface modifying the surface properties, e.g. length of grass, soil moisture etc. Linear regression analysis provides $T_{\text {diffmax }} / \eta_{\max }=0.59$ for asphalt, which is larger than for cobble stones (Lindberg et al. 2008) (Table 1) and 0.21 for grass. The intercept of $\mathrm{T}_{\text {diffmax }}\left(T_{\text {start }}\right)$ for asphalt is $-10.12^{\circ} \mathrm{C}$, which is much smaller than that for cobble stones, while $T_{\text {start }}$ for grass is $-3.38^{\circ} \mathrm{C}$.

\subsection{Model evaluation data}

To evaluate the new land cover scheme in SOLWEIG, data were collected in the Barbican Estate in London, UK in the summer of 2014. The Barbican Complex is a prominent example of British brutalist architecture and consists of three tower blocks (42 storeys and 123 metres high) and 13 terrace blocks ( 8 storeys and 35 metres high). Diurnal observations were undertaken at two locations selected based on differences in surface cover within the estate. Nocturnal observations of $3 \mathrm{D}$ radiation fluxes are extremely rare (see the exception for one diurnal cycle of Ali-Toudert and Mayer 2007). Observations were taken at a well maintained grass surface in Thomas More Residents' garden (Site 1 in Figure 4b) and an elevated playground belonging to the City of London School for Girls (Site 2 in Figure 4b) (referred to hereafter as the podium). The garden soil is a silty loam with a relatively high sand content. The playground (podium) is covered with dark tiles and underneath is a school lecture hall. The three tower blocks are located north of the two sites. The vegetation is almost exclusively deciduous trees and bushes. The spatial elevation data used as input originated from a gridded dataset derived from LiDAR scanning conducted on behalf of the Greater London Authority (GLA). The original gridded dataset consisted of all objects, including both buildings and vegetation. To derive DSM, CDSM and TDSM (Trunk zone Digital Surface Model) the techniques as described in Lindberg and Grimmond (2011a) were used (Figure 4a). The 651 by 601 grid point model domain is has a spatial resolution of $1 \mathrm{~m}$. The land cover data were extracted from the OS MasterMap® Topography Layer (Ordnance Survey 2010). The garden site was surrounded by grass and the podium consisted of dark red tiles and was classified as asphalt in the model evaluation.

The meteorological forcing data are from a climate station on the roof of the Strand Campus at King's College London, $1700 \mathrm{~m}$ WSW of the study area (see e.g. Kotthaus and Grimmond 2014). Air temperature and humidity data were collected using a Vaisala WXT520 and the global and diffuse radiation using a SPN1 Sunshine pyranometer (Delta-T Devices). The mobile station, located at the two Barbican sites (Figure 4b), had three net radiometers (Kipp \& Zonen, CNR 1) to measure the 3-d radiation fields (Thorsson et al. 2007a). The sensors were oriented to measure shortwave and longwave radiation fluxes from the four cardinal points, as well as parallel to the ground surface (incoming and outgoing). An Apogee infrared temperature sensor directed downwards measured surface temperature. A grey globe thermometer as described in Thorsson et al. (2007a) measured globe temperature and a Rotronic HydroClip2 (HC2-S3) air temperature and relative humidity. The two sites were chosen with the expectation that different ground cover would have large effects on the observed radiative fluxes and $T_{m r t}$. For model evaluation, data from integral radiation measurements within the model domain were used. Measurements were taken over 4 days at the grass site (SITE1 in Figure 4b) and 6 days at (SITE2 in Figure 4b) site in summer of 2014. All data were averaged to 15 minute intervals (sample rate $5 \mathrm{sec}$ ), the resolution of model runs. Unfavourable weather and technical issues with sensors resulted in the availability of $15 \mathrm{~min}$ data for the evaluation dataset of 441 data points $(78.5 \%$ of the total).

\section{RESULTS AND DISCUSSION}

\subsection{The influence of ground cover on $\mathbf{T}_{\mathrm{mrt}}$}

With SOLWEIG, insights with respect to ground cover on the radiant fluxes as well as $T_{m r t}$ are now possible. The model has also been developed as a simplified version, SOLWEIG1D (Lindberg 2012). The latter can be used to calculate radiation fluxes and $T_{m r t}$ for a generic sunlit location within the urban environment. The simplified version has a single, fixed, user-specified SVF and the location is assumed to be sunlit during the daytime hours. Realistically, (when SVF $<1$ ) surrounding objects block the sun at certain times of the day and year when SOLWEIG1D was run with the same settings 
(Section 2). Figure 5 shows the differences in surface temperature of different ground surfaces for a location in Gothenburg (Sweden) when fully sunlit with a SVF set to 0.60 . This example day is a clear summer day with very low diffuse shortwave radiation (approx. $104 \mathrm{~W} \mathrm{~m}^{-2}$ at noon), and high direct component on a surface perpendicular to the Sun ( $878 \mathrm{~W} \mathrm{~m}^{-2}$ at noon) (Figure 5, left). The evolution of daytime surface temperatures varies between $31.6^{\circ} \mathrm{C}$ (grass) and $45.6^{\circ} \mathrm{C}$ (dark asphalt) for the sunlit locations at $2 \mathrm{pm}$ (Figure 5, middle). A shadowed location follows same evolution of air temperature during day, reaching a maximum of $23.5^{\circ} \mathrm{C}$.

With respect to differences in $T_{m r t}$ (Figure 5, right) over the surface materials included the ground cover scheme considered, the largest discrepancies from the original model are found for the grass surface $\left(-5.2^{\circ} \mathrm{C}\right.$ at $\left.4 \mathrm{pm}\right)$. The differences between the cobble stone and dark asphalt are smaller $\left(1.5^{\circ} \mathrm{C}\right.$ at $\left.4 \mathrm{pm}\right)$. The variation of $T_{m r t}$ over different ground surfaces at sunlit locations are very small compared to a shadowed location $\left(-38.2^{\circ} \mathrm{C}\right.$ at $\left.4 \mathrm{pm}\right)$. This large difference is well known (Ali-Toudert and Mayer 2007; Pearlmutter et al. 2007; Krüger et al. 2011) and attributed primarily to the absence of the direct shortwave component but also the reduction of ground surface temperatures and thus outgoing longwave radiation fluxes.

A simple approach is taken to estimate water temperature that could be modified based on time of year, water volume, movement of water etc. Future versions will address this (e.g. following Cluis 1972). Nevertheless, given the radiation fluxes seem only to have a small effect on the resulting $T_{m r t}$, the simple estimation of water temperature is considered acceptable. Moreover, as the simulations of ambient air temperature are not spatially variable across the model domain, the water temperature does not influence air temperature.

\subsection{Observations and model evaluation of $\mathbf{T}_{\text {mrt }}$ in a complex urban environment}

To evaluate the model the Barbican (section 2.4) observations were used. Incoming and outgoing radiation fluxes as well as $T_{m r t}$ on the Barbican podium and in the garden are shown in Figure 6 and Figure 7, respectively. The shortwave fluxes are influenced by the shadows as well as the albedo of the surrounding surfaces (Fig 6a, 8a). The high accuracy and precision of the surface data used are evident, for example the morning of 11 July on the podium, when the timing of observed and modelled incoming shortwave radiation affected by shadowing is almost identical (Fig 6a). With forcing data for model runs from $1 \mathrm{~km}$ away (Section 2.4), the difference in cloudiness are apparent. For the podium site, this is seen frequently in the afternoon of the 11 July and thereafter (Fig 6). When totally overcast (10 July), the discrepancies due to cloudiness between the two sites are not seen. Similar patterns are seen for the garden evaluation (Fig 7), especially for 16 July where the differences at times (e.g. before noon) are very large. The albedo used for the podium surface (Table 1) resulted in a minor overestimation of outgoing shortwave radiation, whereas the value for the grass surface gave a small underestimation. However, as the outgoing shortwave radiation fluxes are very small compared to the other fluxes, the model is not particularly sensitive to albedo values.

Incoming longwave radiation fluxes $\left(L_{\text {down }}\right)$ are not impacted by the modification (eq. 4$)$. A clear pattern is evident where cloudiness (incoming shortwave radiation) affects the variability of $L_{\text {down }}$. To estimate $L_{d o w n}$ at night, a parameterisation of cloudiness is implemented (Lindberg and Grimmond 2011b) to estimate incoming long-wave radiation fluxes. Here, the concept from Offerle et al. (2003) is used where cloudiness up to midnight is taken from clearness index calculations from the last hour on the day (i.e. just before sunset). The cloudiness after midnight is taken from clearness index values the first hour of the next day (i.e. just after sunrise). Nevertheless, the levels of $L_{\text {down }}$ are estimated relatively well. As reported by Jonsson et al. (2006), the clear-sky formula developed by Prata (1996), overestimates the sky emissivity during daytime by 0.04 . This is not accounted for in this study but can be by implemented by future users of the model (see Section 3.3). The general adjustment of $L_{\text {down }}$ by $25 \mathrm{~W} \mathrm{~m}^{-2}$ (Lindberg et al. 2008) was removed, from SOLWEIG version 2015a, as this reduction has no physical explanation. The outgoing longwave radiation fluxes $\left(L_{u p}\right)$ are the fluxes that are affected the most by the new equations. As seen in Figure $6 \mathrm{~b}, L_{u p}$ at the podium shows a great improvement with respect to the rise of $L_{u p}$ during the morning hours (e.g. $11^{\text {th }}$ and $13^{\text {th }}$ of July). For example, the difference between observed and modelled is reduced from 71 to $5 \mathrm{~W} \mathrm{~m}^{-2}$ at $2 \mathrm{pm}$ on the 13 July. However, the afternoon reduction of $L_{u p}$ due to cloudiness is not captured equally well (e.g. $60 \mathrm{~W} \mathrm{~m}^{-2}$ at $6 \mathrm{pm}$ on $13 \mathrm{July}$ ). The same reduction is captured better for the grass surface in the garden (Fig 7) where discrepancies between observed and modelled values are around $13 \mathrm{~W}$ $\mathrm{m}^{-2}$. This difference in reduction between the two sites is probably due to the heat storage capabilities of the two surfaces, as well as the fact that the podium is situated on a roof and probably affected by the underlying lecture hall. This can also be seen throughout the night (Fig 6), when the observed $L_{u p}$ is considerably higher than modelled $L_{u p}$. This discrepancy is considerably smaller in the garden, probably due both to differences in heat storage capabilities as well as its location on the ground (i.e. no underlying indoor environment). Daytime $L_{u p}$ in the garden is underestimated in the model. This is a consequence of the difference in grass surfaces between the parameterisation site in Gothenburg and the grass surface in the garden, both with respect to levels of maintenance, soil type and soil moisture availability during the observations in London. The largest difference between modelled and observed $L_{u p}$ is found on the $16^{\text {th }}$ of July. Sometimes the grass in 
the garden shows higher surface temperature and $L_{u p}$ than the cobble stone surface used in the original SOLWEIG model. However, these large differences which $\left(>600 \mathrm{~W} \mathrm{~m}^{-2}\right)$, are related more to differences in $K_{\text {down }}$ between the forcing data site and the observation site. Nevertheless, the underestimation of $L_{u p}$ is evident on the other observation days (e.g. $8^{\text {th }}$ of July). Thus, based on the observations made in the garden, maintained and unmaintained grass surface have different set of parameters. This result suggests that introducing highly maintained grass surfaces in the urban environment will have a very small effect on reducing $T_{m r t}$ during heat waves, for example, when these surfaces in general may be dried out and very warm.

In SOLWEIG, the nocturnal surface temperature of ground and walls are set equal to air temperature. This approximation seems to be inaccurate for the podium. However, estimating surface temperature and hence $L_{u p}$ on a roof is very complex and a much more complex surface temperature scheme would be needed such as, for example, the Town Energy Balance model (TEB) (Masson 2000) or a building energy model. However, these models are designed to work at the local-scale, not micro-scale that is of interest here. This would slow down the calculations considerably since calculations would need to be performed for every time step and pixel. In modelling schemes such as TEB, only one calculation is performed every time step and for each facet (roof, wall and ground). One possibility would be not to do a pixel wise surface temperature estimation but to consider a number of general surfaces (e.g. shaded/sunlit asphalt, shaded/sunlit grass) etc. Another possibility would be to use a 3D computationally fluid dynamics approach such as the ENVI-Met model (Bruse and Fleer 1998) which will increase computation complexity dramatically. The advantage of using the simple surface temperature scheme in SOLWEIG makes it possible to examine micro-scale radiation fluxes at pedestrian level for relatively extensive areas.

The outgoing radiative fluxes also, to a small extent, affect the fluxes from the cardinal points (not shown). When the radiation fluxes from the four cardinal points are estimated, a portion of the ground is not accounted for. As only 20 times of $\mathrm{z}(1.1 \mathrm{~m})$ is searched in each direction, the portion of the ground furthest away from the point of interest is not accounted for. However, this portion of field of view is very small and only accounts for about $3.3 \%$. Nevertheless, this area is almost perpendicular to the surface considered and might have a small effect on the total flux from the cardinal points.

By combining the radiation fluxes, $T_{m r t}$ can be calculated. The calculated $T_{m r t}$ on the podium compares very well for sunlit conditions (Figure 8), whereas shadowed and nocturnal values (maximum difference up to $10^{\circ} \mathrm{C}$ during night) are underestimated relative to the observations, as the simplification of setting surface temperature equal to air temperature result in an underestimation of $L_{u p}$ (Figure 6). $T_{m r t}$ in the garden is underestimated during clear sky conditions, as the different properties of the grass surfaces affecting $L_{u p}$ are evident (Figure 7). The 15 min resolution sometimes results in very large discrepancies between the forcing of $K_{\text {down }}$ at the Strand Campus, King's College London and the observed $K_{\text {down }}$ in the Barbican Estate. This makes it difficult to evaluate the land cover scheme in detail. This is most evident on the $16^{\text {th }}$ of July in the garden where $T_{m r t}$ is underestimated. This also contributes to the large scatter evident in Figure 8. $T_{m r t}$ observed from the more simple method using just a globe temperature, air temperature and wind speed observations (Nikolopoulou et al. 1999; Thorsson et al. 2007a) has very good performance when compared to the integral six-direction observations $\left(\mathrm{R}^{2}=0.96\right.$, Slope $=1.001$, Intercept $\left.=-1.3 \mathrm{~K}\right)$.

\subsection{Model accessibility through user-friendly interfaces}

Users can apply the SOLWEIG model via a graphical user interface (GUI) exploiting the Matlab compiler runtime environment. This is freely available for download (http://gvc.gu.se/english/research/climate/urban-climate). It will also be incorporated into the Urban Multi-scale Environmental Predictor (UMEP), a climate service tool, designed for researchers, architects and urban planners (Lindberg et al. 2015b). This tool can be used for a variety of applications related to outdoor thermal comfort, urban energy consumption, climate change mitigation etc. UMEP consists of a coupled modelling system which combines "state of the art" 1D and 2D models related to the processes essential for scale independent urban climate estimations. UMEP is a community, open source model, where users can contribute as well as extend the tool to improve modelling capabilities. This is freely available for download

(https://bitbucket.org/fredrik_ucg/umep). A major feature is the ability for a user to interact with spatial information to determine model parameters. The spatial data across a range of scales and sources are accessed through QGIS (QGIS Development Team, 2015) - a cross-platform, free, open source desktop geographic information systems (GIS) application - that provides data viewing, editing, and analysis capabilities. QGIS is both extendable by plugins plus reducible to only essential core features needed.

\section{CONCLUSIONS AND FUTURE DEVELOPMENTS}

The effect of variations in land surface cover on $T_{m r t}$ is explored for three cover types within the SOLWEIG model. Outgoing longwave radiation is parameterised (using near surface temperature observations for grass and asphalt surfaces), and outgoing shortwave radiation now allows variations in albedo for the different surfaces. Improvements to the longwave radiation are also included. The influence of land cover on $T_{m r t}$ is small (about $5^{\circ} \mathrm{C}$ ) compared to shadowing (about $30^{\circ} \mathrm{C}$ ). The results suggest that altering of ground surface materials is not as an effective measure as 
shadowing to reduce the radiant load during heat-wave episodes. Nevertheless, altering ground surface materials could contribute to a significant reduction on $T_{m r t}$ in areas where shadowing is not an option.

Evaluation of the land cover scheme shows that despite its simplicity, it can simulate the outgoing fluxes well, especially for sunny conditions. Underestimations are evident at night and for shadowed locations. The grass surface used for the parameterisation had very different characteristics compared to the grass surface where the evaluation observations were made, which probably explains the underestimation of $T_{m r t}$ over that grass surface. The implications of using $15 \mathrm{~min}$ temporal data is demonstrated for partly cloudy conditions for a situation with only a relatively short distance between the location of the forcing data of incoming shortwave radiation and evaluation data (up to $600 \mathrm{~W} \mathrm{~m}^{-2}$ difference).

Further developments needed include improvements of nocturnal estimations of $T_{m r t}$ as well as inclusion of a simple water temperature scheme. Furthermore, promising work (Holmer et al. 2015) to eliminate the fact that the formula by Höppe (1992) describes the human shape as a box and not a cylinder (as noted by Kántor et al. 2014) is currently being developed. This assumption has resulted in some peculiar features noted in studies of $T_{m r t}$ such as a local minimum at noon (e.g. Thorsson et al. 2007; Kántor et al. 2014).

\section{Acknowledgements}

This work is financially supported by FORMAS - the Swedish Research Council for Environment, Agricultural Sciences and Spatial Planning, H2020-EO-1-2014 Project 637519: URBANFLUXES and Newton Fund/Met Office Climate Services CSSP - China. Many thanks to William Morrison and the many others at University of Reading who maintain LUMA data collection, Barbican Estate and City of London Girls School for providing the data. URBANFLUXES is co-financed by "HORIZON 2020" EU Framework Programme.

\section{REFERENCES}

Ali-Toudert, F., and H. Mayer, 2007: Thermal comfort in an east-west oriented street canyon in Freiburg (Germany) under hot summer conditions. Theoretical and Applied Climatology, 87, 223-237.

Andersson-Sköld, Y., and Coauthors, 2015: An integrated method for assessing climate-related risks and adaptation alternatives in urban areas. Climate Risk Management.

Bogren, J., T. Gustavsson, M. Karlsson, and U. Postgård, 2000: The Impact of Screening on Road Surface Temperature. Meteorological Applications, 7, 97-104.

Bruse, M., and H. Fleer, 1998: Simulating surface-plant-air interactions inside urban environments with a three dimensional numerical model. Environmental Modelling and Software, 13, 373-384.

Chen Y-C, Lin T-P, Matzarakis A. Comparison of mean radiant temperature from field experiment and modelling: a case study in Freiburg, Germany. Theoretical and Applied Climatology. 2014.

Cluis, D. A., 1972: Relationship between stream water temperature and ambient air temperature - A Simple Autoregressive Model for Mean Daily Stream Water Temperature Fluctuations. Nordic Hydrology, 3, 65-71.

Crawford, T. M., and C. E. Duchon, 1999: An improved parameterization for estimating effective atmospheric emissivity for use in calculating daytime downwelling longwave radiation. Journal of Applied Meteorology, 38, 474-480.

Erell, E., D. Pearlmutter, D. Boneh, and P. B. Kutiel, 2014: Effect of high-albedo materials on pedestrian heat stress in urban street canyons. Urban Climate. 10, 367-386.

Fanger, P. O., 1970: Thermal comfort. 256 pp.

Holmer, B., Lindberg, F., Rayner, D. and Thorsson, S. 2015: How to transform the standing man from a box to a cylinder - a modified methodology to calculate mean radiant temperature in field studies and models, ICUC9 - 9 th International Conference on Urban Climate jointly with AMS 12th Symposium on the Urban Environment, BPH5: Human perception and new indicators. Toulouse, July 2015.

Höppe, P., 1992: A new procedure to determine the mean radiant temperature outdoors. Wetter unt Leben, 44, 147-151.

Jonsson, P., I. Eliasson, B. Holmer, and C. S. B. Grimmond, 2006: Longwave incoming radiation in the Tropics: results from field work in three African cities. Theoretical and Applied Climatology, 85, 185-201.

Kántor, N., T.-P. Lin, and A. Matzarakis, 2014: Daytime relapse of the mean radiant temperature based on the six-directional method under unobstructed solar radiation. International Journal of Biometeorology, 58, 1615-1625.

Konarska, J., F. Lindberg, A. Larsson, S. Thorsson, and B. Holmer, 2014: Transmissivity of solar radiation through crowns of single urban trees - application for outdoor thermal comfort modelling. Theoretical and Applied Climatology, 117, 363-376.

Kotthaus, S. and C. S. B. Grimmond, 2014: Energy exchange in a dense urban environment - Part I: Temporal variability of long-term observations in central London. Urban Climate 10:2, 262-280.

Krüger, E. L., F. O. Minella, and F. Rasia, 2011: Impact of urban geometry on outdoor thermal comfort and air quality from field measurements in Curitiba, Brazil. Building and Environment, 46, 621-634.

Lau KK-L, Ren C, Ho J, Ng E. Numerical modelling of mean radiant temperature in high-density sub-tropical urban environment. Energy and Buildings. 2015.

Lindberg, F., and C. S. B. Grimmond, 2010: Continuous Sky View Factor Maps from High Resolution Urban Digital Elevation Models. Climate Research, 42, 177-183.

Lindberg, F., and C. S. B. Grimmond, 2011a: Nature of vegetation and building morphology characteristics across a city: Influence on shadow patterns and mean radiant temperatures in London. Urban Ecosystems, 14, 617-634.

Lindberg, F., and C. S. B. Grimmond, 2011b: The influence of vegetation and building morphology on shadow patterns and mean radiant temperatures in urban areas: model development and evaluation. Theoretical And Applied Climatology, 105, 311-323. 
Lindberg, F., B. Holmer, and S. Thorsson, 2008: SOLWEIG 1.0 - Modelling spatial variations of 3D radiant fluxes and mean radiant temperature in complex urban settings. International Journal of Biometeorology, 52, 697-713.

Lindberg, F., B. Holmer, S. Thorsson, and D. Rayner, 2013: Characteristics of the mean radiant temperature in high latitude citiesimplications for sensitive climate planning applications. International Journal Of Biometeorology, 1-15.

Lindberg, F., P. Jonsson, T. Honjo, and D. Wästberg, 2015a: Solar energy on building envelopes - 3D modelling in a 2D environment. Solar Energy, 115, 369-378.

Lindberg, F., Grimmond, CSB., Onomura, S., Järvi, L. and Ward, H. 2015b: UMEP - An integrated tool for urban climatology and climate-sensitive planning applications. ICUC9 - 9 th International Conference on Urban Climate jointly with 12th Symposium on the Urban Environment, TUKUP7 (cont): Warning plans \& Decision support tools. Toulouse, July 2015.

Masson, V., 2000: A Physically-Based Scheme For The Urban Energy Budget In Atmospheric Models. Boundary-Layer Meteorology, 94, 357-397.

Matzarakis, A., F. Rutz, and H. Mayer, 2007: Modelling radiation fluxes in simple and complex environments - application of the RayMan model. International Journal of Biometeorology, 51, 323-334.

Matzarakis, A., F. Rutz, and H. Mayer, 2009: Modelling radiation fluxes in simple and complex environments: basics of the RayMan model. International Journal Of Biometeorology, 54, 131-139.

Mayer, H., and P. Höppe, 1987: Thermal comfort of man in different urban environments. Theoretical and Applied Climatology, 38, 43-49.

Mayer, H., J. Holst, P. Dostal, F. Imbery, and D. Schindler, 2008: Human thermal comfort in summer within an urban street canyon in Central Europe. Meteorol. Z., 17, 241-250.

Müller N, Kuttler W, Barlag A-B. Counteracting urban climate change: adaptation measures and their effect on thermal comfort. Theoretical and Applied Climatology. 2013;115(1-2):243-57.

Nikolopoulou, N., N. Baker, and K. Steemers, 1999: Improvements to the globe thermometer for outdoor use. Architectural Science Review, 42, 27-34.

Offerle B, Grimmond CSB, Oke TR, 2003: Parameterization of net allwave radiation for urban areas. J Appl Meteorol 42:1157-1173.

Oke T (1987) Boundary layer climates. Routledge, Cambridge, p 435

Ordnance Survey, cited 2009: (C) Crown database right 2010. An Ordnance Survey/EDINA supplied service. [Available online at http://www.ordnancesurvey.co.uk/oswebsite/.]

Pearlmutter, D., P. Berliner, and E. Shaviv, 2007: Integrated modeling of pedestrian energy exchange and thermal comfort in urban street canyons. Building and Environment, 42, 2396-2409.

Prata, A. J., 1996: A new long-wave formula for estimating downward clear-sky radiation at the surface. Quarterly Journal of the Royal Meteorological Society, 122, 1127-1151.

QGIS Development Team, 2015. QGIS Geographic Information System. Open Source Geospatial Foundation Project. http://qgis.osgeo.org

Ratti, C. F., and P. Richens, 1999: Urban texture analysis with image processing techniques. Proc CAADFutures99, Atalanta, GA.

Ratti, C. F., and P. Richens, 2004: Raster analysis of urban form. Environment and Planning B-Planning \& Design, 31, $297-309$.

Reindl, D. T., W. A. Beckman, and J. A. Duffie, 1990: Diffuse fraction correlation. Solar energy, 45, 1-7.

Schmid, H. P., H. A. Cleugh, C. S. B. Grimmond, and T. R. Oke, 1991: Spatial variability of energy fluxes in suburban terrain. Bound.-Layer Meteor., 54, 249-276.

Thorsson, S., F. Lindberg, I. Eliasson, and B. Holmer, 2007a: Different methods for estimating the mean radiant temperature in an outdoor urban setting. International Journal Of Climatology, 27, 1983-1993.

Thorsson, S., J. Rocklöv, J. Konarska, F. Lindberg, B. Holmer, B. Dousset, and D. Rayner, 2014: Mean radiant temperature - A predictor of heat related mortality. Urban Climate, 10, Part 2, 332-345.

VDI, 1998: Methods for the human-biometeorological assessment of climate and air hygiene for urban and regional planning. Part I: Climate. VDI 3787, Part 2, Belin 29p.

Table 1. Characteristics for the different land cover types used in this study. The three last columns are derived from observation. Emissivity and albedo values are from Oke (1987). See text for further explanation.

\begin{tabular}{|l|c|c|c|c|c|}
\hline & $\begin{array}{c}\text { Emissivity } \\
(\varepsilon)\end{array}$ & Albedo $(\alpha)$ & $\begin{array}{c}\mathrm{T}_{\mathrm{s}} / \eta_{\max } \\
\left({ }^{\circ} \mathrm{C}\right)\end{array}$ & $\begin{array}{c}T_{\text {start }} \\
\left({ }^{\circ} \mathrm{C}\right)\end{array}$ & $\begin{array}{c}\text { Time of } T_{\text {diffmax }} \\
(\text { Local time, } \mathrm{h})\end{array}$ \\
\hline Asphalt & 0.95 & 0.18 & 0.59 & -10.12 & 15 \\
\hline $\begin{array}{l}\text { Cobble stones (Lindberg et al. } \\
\text { 2008) }\end{array}$ & 0.95 & 0.20 & 0.37 & -3.41 & 14 \\
\hline Grass & 0.94 & 0.16 & 0.21 & -3.38 & 14 \\
\hline Water & 0.98 & 0.05 & 0.00 & 0.00 & $\mathrm{NA}$ \\
\hline
\end{tabular}


Figure 1. Example grids used to estimate outgoing shortwave radiation. a) digital surface models (DSM and CDSM), b) shadow patterns at 1 pm 26 July 2006 in Gothenburg (Sweden), c) land cover, d) albedo dependent ground view factor (GVF) for sunlit surfaces $\left(\Psi_{g S u n l i t(\alpha)}\right)$ at $\left.1 \mathrm{pm}, \mathbf{e}\right)$ albedo dependent ground view factor for all ground pixels $\left(\Psi_{g A l l(\alpha)}\right)$ and $\left.\mathbf{f}\right)$ outgoing shortwave radiation ( $\mathrm{W} \mathrm{m}^{-2}$ ) at $1 \mathrm{pm}$. Model input: $I=728.3 \mathrm{~W} \mathrm{~m}^{-2}, G=766.1 \mathrm{~W} \mathrm{~m}^{-2}$ and $D=194.8 \mathrm{~W} \mathrm{~m}^{-2}$. Pixel resolution is $1 \mathrm{~m}$. See definitions in text.
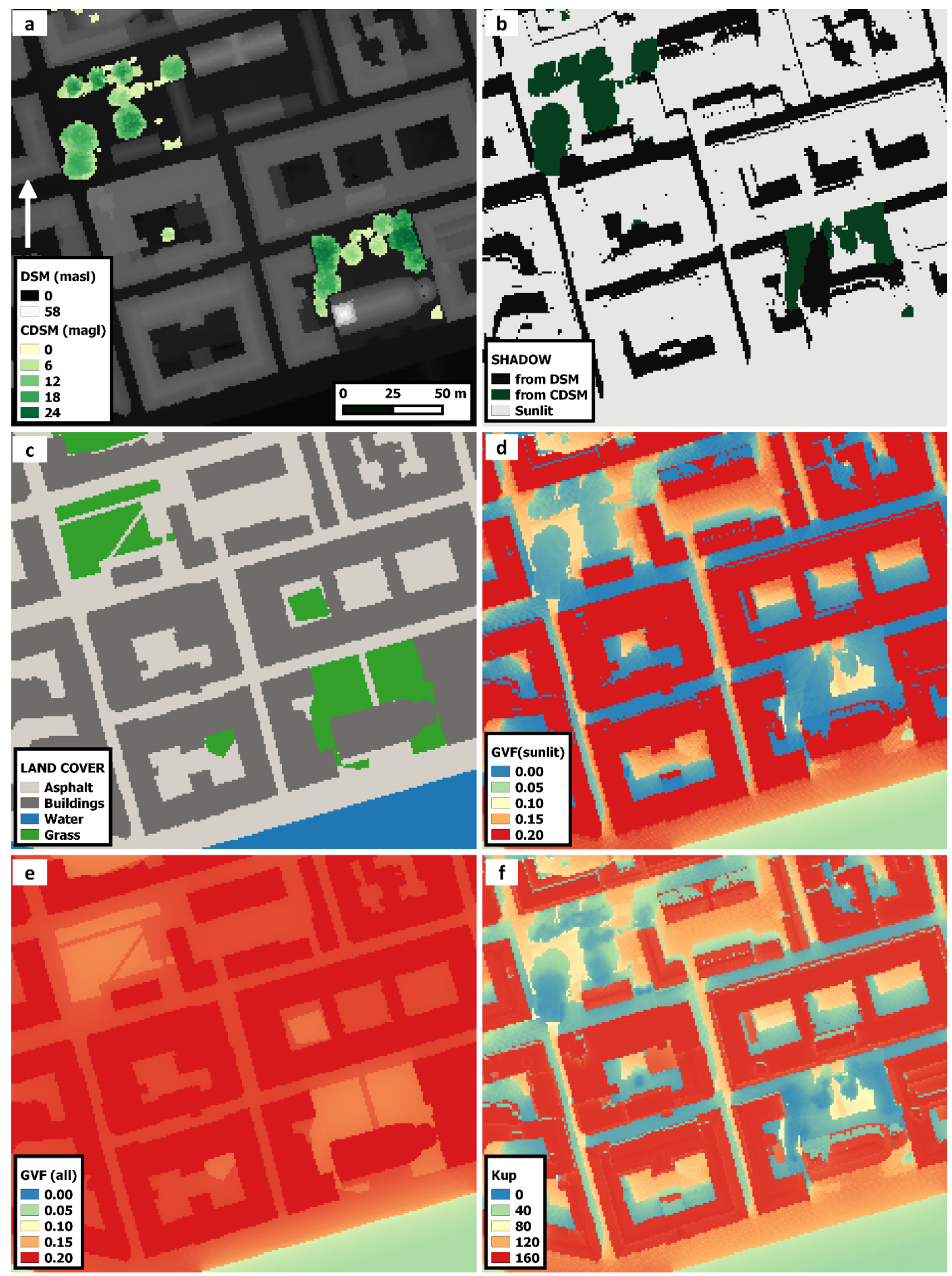
Figure 2. Calculated values for $1 \mathrm{pm} 26$ July 2006 Gothenburg (Sweden) of a) outgoing longwave radiation (W m $\mathrm{m}^{-2}$ ), b) outgoing shortwave radiation $\left(\mathrm{W} \mathrm{m}^{-2}\right)$ from south, $\left.\mathbf{c}\right)$ from north and $\left.\mathbf{d}\right)$ mean radiant temperature, $T_{m r t}\left({ }^{\circ} \mathrm{C}\right)$, for a standing person. Pixel resolution is $1 \mathrm{~m}$.

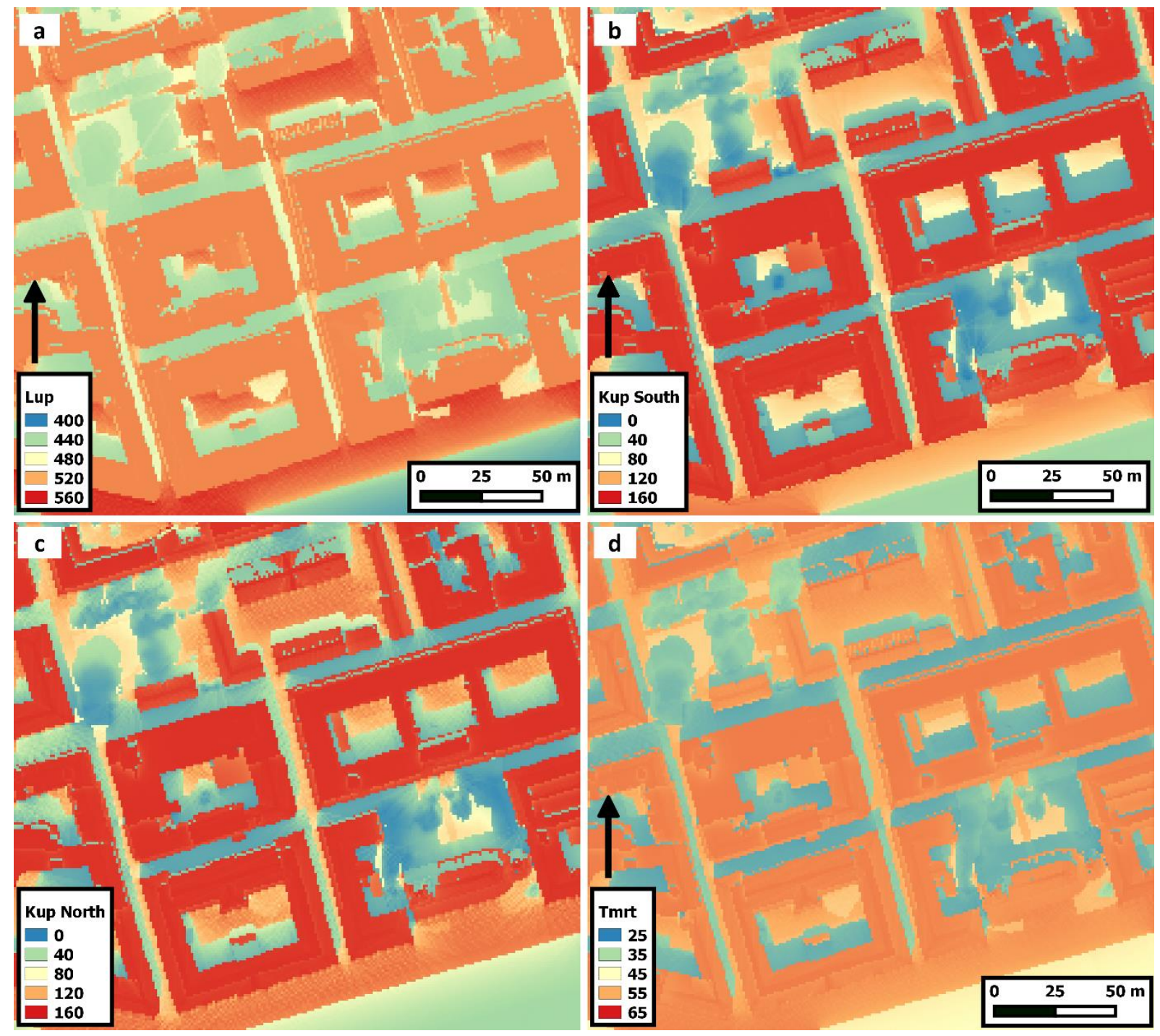

Figure 3. Observed relation of temperature difference between surface a) dark asphalt and $\mathbf{b}$ ) grass and air and maximum sun elevation under clear-sky condition (clearness index > 0.9) in Gothenburg Sweden between 1 July 2011 and 31 December 2012. Each data point is a daily value. 

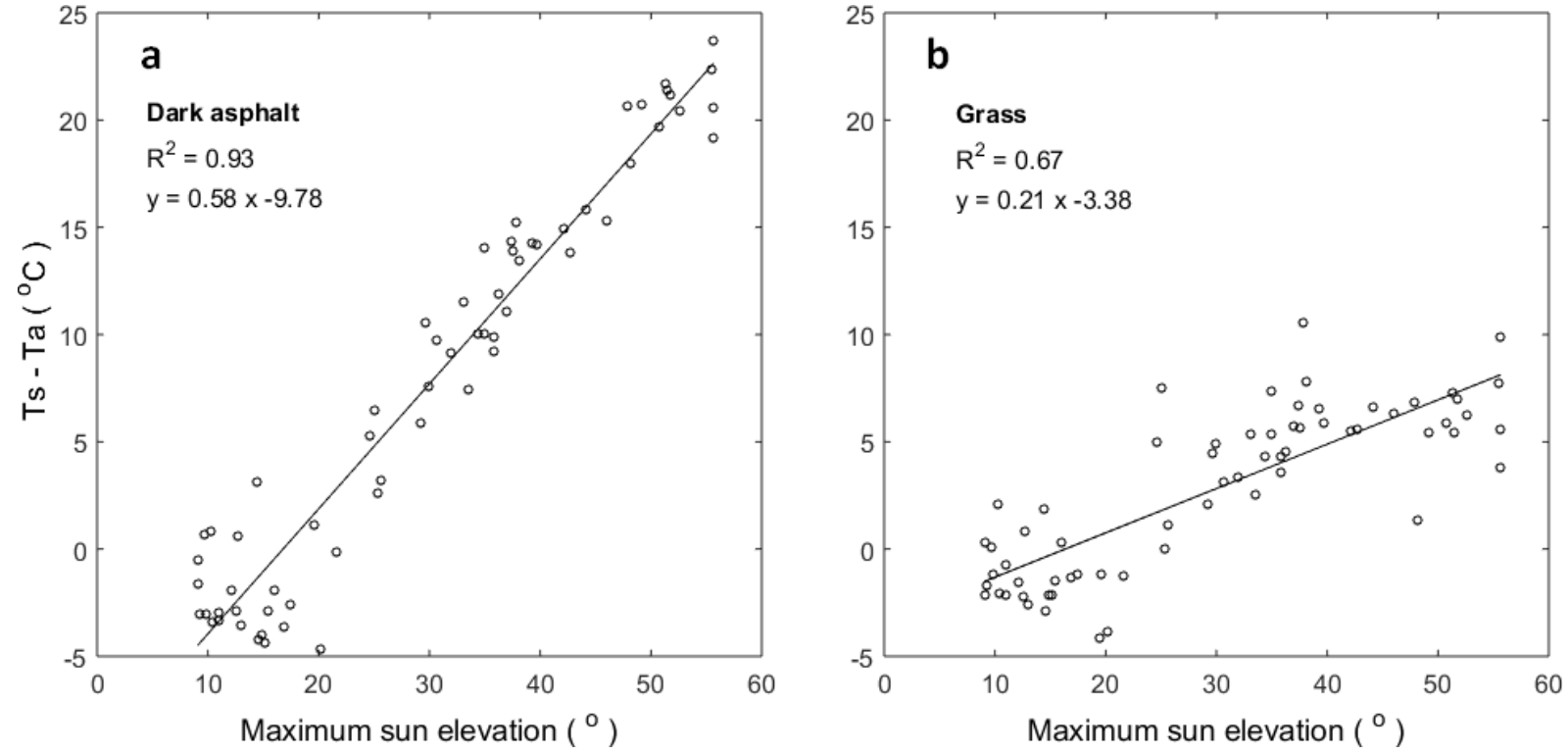

Figure 4. The Barbican Estate study area in London, UK, $\left(51^{\circ} 30^{\prime} \mathrm{N}, 0^{\circ} 7^{\prime} \mathrm{W}\right)$ and model domain with a) building and ground DSM overlain with a vegetation canopy DSM (CDSM) and b) ground cover grid. SITE 1 and 2 are where integral radiation measurements were conducted. Pixel resolution is $1 \mathrm{~m}$.
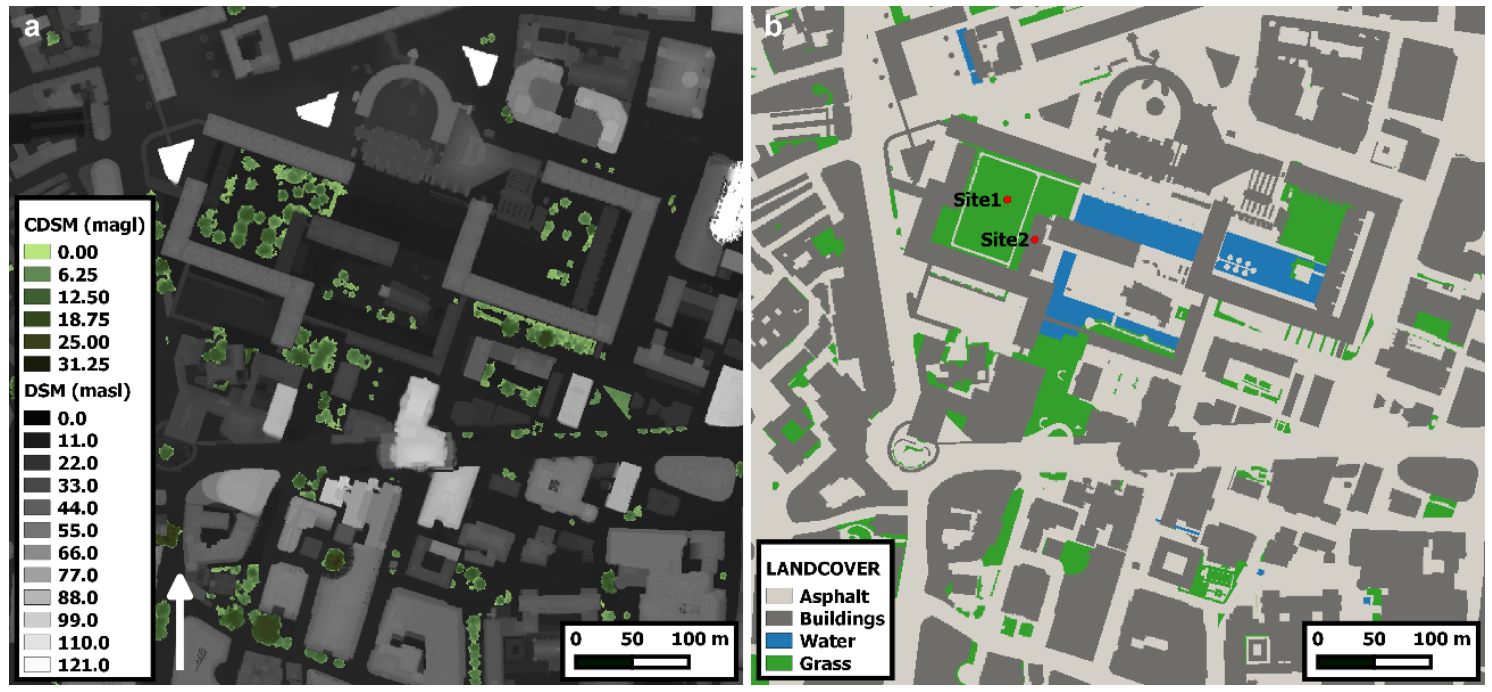

Figure 5. Influence of ground cover on surface temperature and mean radiant temperature on the 6 June 1997 in Gothenburg; a) shortwave radiation components ( $I=$ direct (incidence angle), $G=$ global, $D=$ diffuse), b) surface temperature c) mean radiant temperature $\left(T_{m r t}\right)$. Location is assumed to be fully sunlit with a SVF of 0.60 .
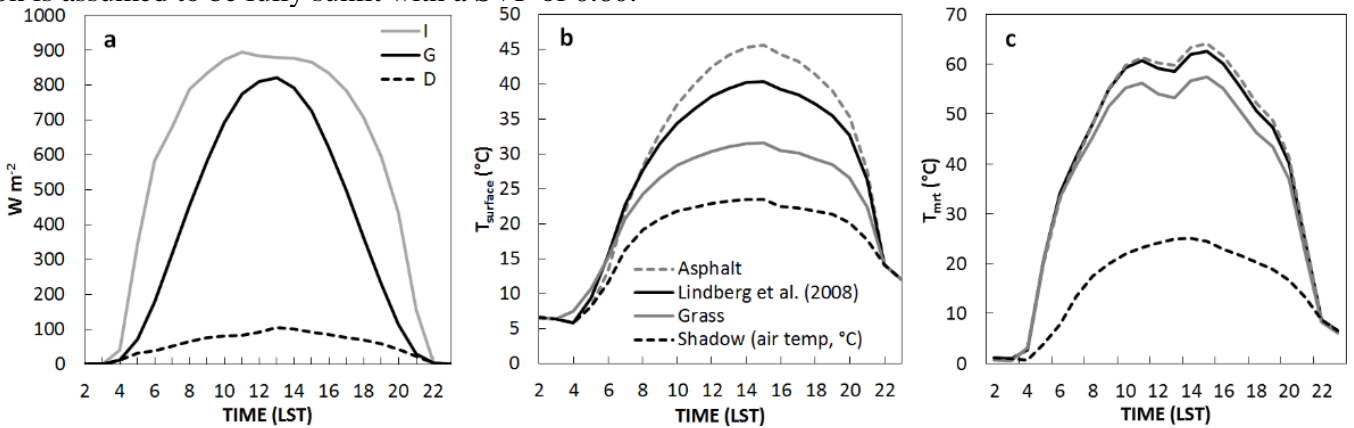

Figure 6. Observed and modelled values of a) incoming and outgoing shortwave, b) longwave radiation fluxes and c) mean radiant temperature $\left(T_{m r t}\right)$ on the elevated podium site in London for five consecutive days in July, 2014. Subscripts: $\bmod$ no $l c$ - without the 
new land cover scheme, $o b s$ - observed from integral radiation measurements, mod - modelled with the new land cover scheme and globe - observed with the globe temperature method (Thorsson et al. 2007).
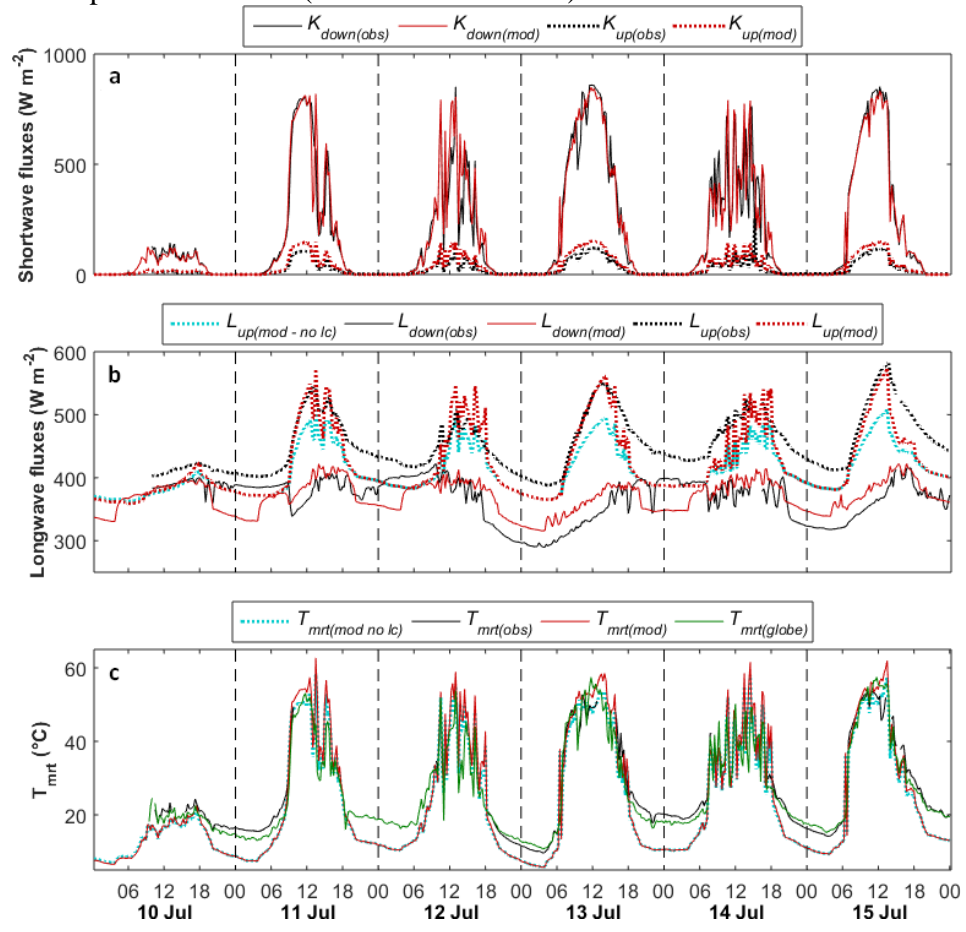
Figure 7. Observed and modelled values of a) incoming and outgoing shortwave, b) longwave radiation fluxes and c) mean radiant temperature $\left(T_{m r t}\right)$ in the garden in London for individual days in July 2014. Subscripts: mod no lc - without the new land cover scheme, $o b s$ - observed from integral radiation measurements, mod-modelled with the new land cover scheme and globe - observed with the globe temperature method (Thorsson et al. 2007).
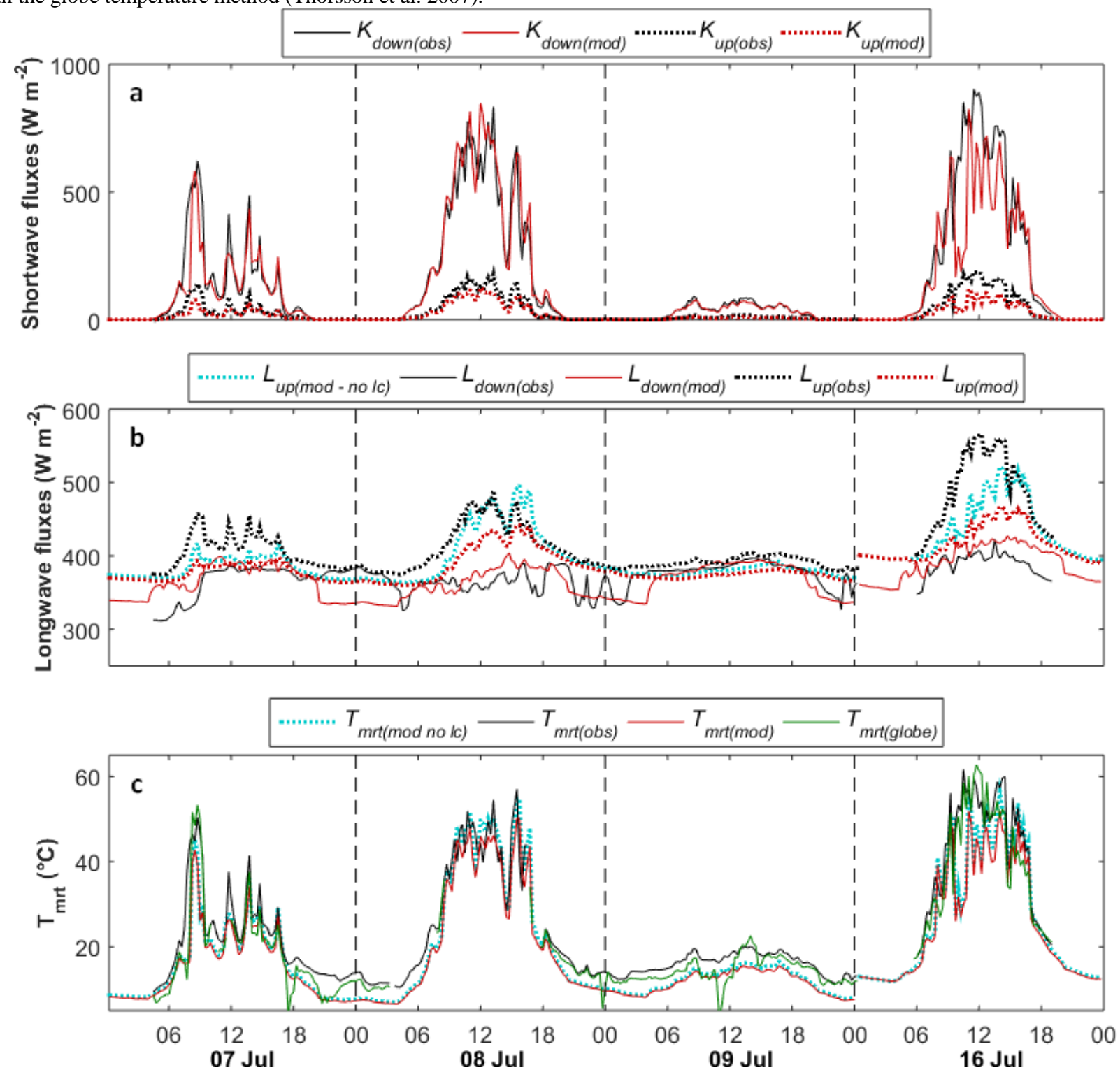

Figure 8. Observed versus modelled 15 min values of mean radiant temperature $\left(T_{m r t}\right)$ for the podium and garden sites ( 7 - 16 July 2014) in London (Fig 4). 

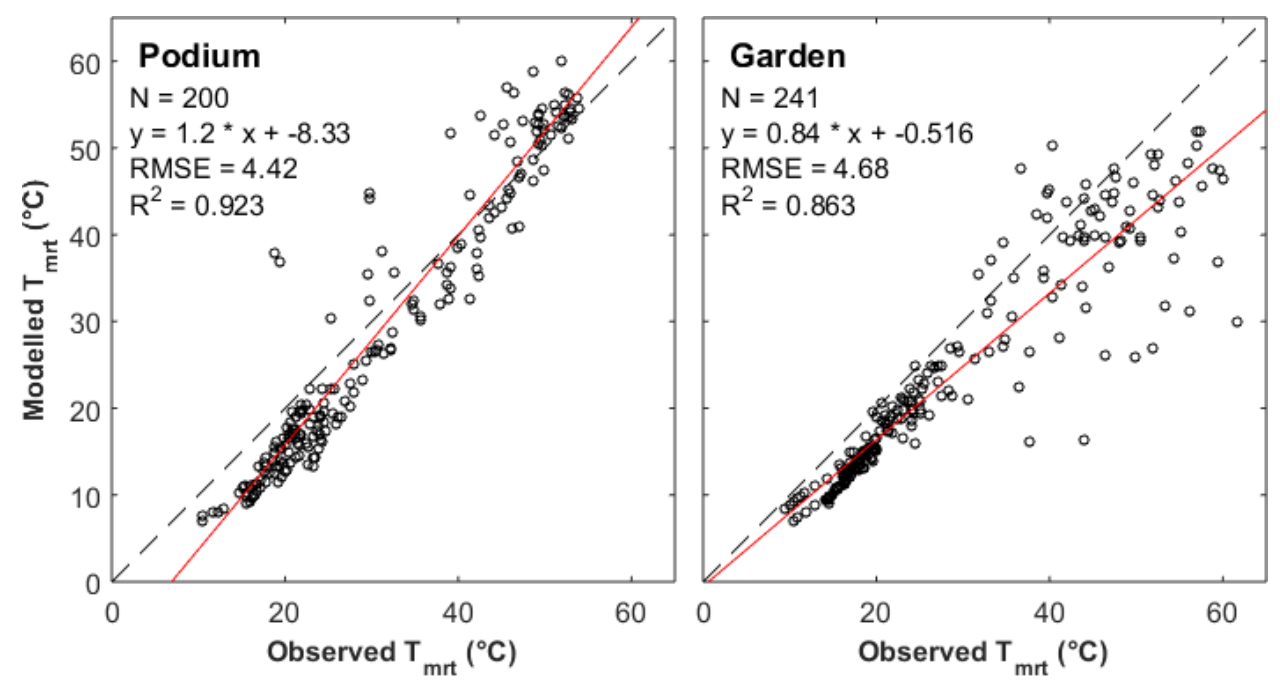